Thorax (1963), 18, 101

\title{
The surgical treatment of acquired aneurysm of the thoracic aorta
}

\author{
C. N. BARNARD AND V. SCHRIRE
}

From the Departments of Surgery and Medicine, University of Cape Town, Council for Scientific and Industrial Research Cardiopulmonary Group, and the Cardiac Clinic, Groote Schuur Hospital, Cape Town, South Africa

The surgical treatment of an aneurysm of the abdominal aorta is a well-established procedure with fairly clear-cut indications and limitations. Treatment of an aneurysm of the thoracic aorta, on the other hand, is a more hazardous procedure that requires partial or total cardiac bypass with hypothermia, either moderate or profound, with or without local cooling of the heart. The reason for this is that the aortic valves, the coronary arteries, and the three major vessels supplying the head, neck, and upper limbs are frequently involved by the disease. In consequence, special perfusion techniques are required to maintain adequate cardiac, brain, and spinal cord function during a prolonged procedure lasting several hours.

In this paper we describe the surgical results in eight consecutive patients with aortic aneurysm. In four of these the ascending aorta was involved with varying degrees of associated aortic incompetence in two, erosion of the sternum and ribs in two, involvement of the innominate artery in one, perforation into the superior vena cava in one, and obstruction of the pulmonary artery and right ventricle in one. In four, varying lengths of the descending aorta were involved, the proximal aorta being affected in three of the four patients, with involvement of the lung and/or thoracic vertebrae in all. Two of these patients had no associated aortic incompetence.

\section{CASE REPORTS}

CASE 1 V.M., a coloured man of 44 years, was admitted on 2 May 1961 in severe distress. Mild inconstant central chest pain, radiating to the shoulders, and dysphagia had commenced fairly acutely one month before. On the day his symptoms began his wife noticed swelling of his face and the right side of his neck, followed by bilateral jugular venous distension. Severe effort dyspnoea and orthopnoea developed rapidly and persisted after the pain and dysphagia had disappeared. Severe bilateral shoulder pain then recurred, requiring admission elsewhere and pethidine administration.
At this stage the clinical picture of superior mediastinal obstruction was present, and a continuous murmur was audible in the right parasternal and aortic areas. Treatment with iodide, mercury, penicillin, and mercurial diuretics was begun. When he continued to deteriorate he was referred to the cardiac clinic.

On examination he was almost moribund. The face, neck, upper trunk, and upper limbs were very oedematous. The veins draining into the superior vena cava were dilated and non-pulsatile. The blood pressure in both arms was equal, $165 / 80 \mathrm{~mm}$. $\mathrm{Hg}$. There was no cardiomegaly and no valve murmurs. In the right lower neck and intraclavicular area a continuous thrill and murmur indicative of an arterio-venous fistula was present. Moderate hepatomegaly was noted. The electrocardiogram showed right ventricular dilatation and on radiography (Fig. 1A) the superior mediastinal shadow was widened.

The diagnosis of ruptured aortic aneurysm into the superior vena cava or innominate vein was made and immediate surgery advised. The serology was positive for syphilis, the sedimentation rate was $52 \mathrm{~mm}$./hour and the leucocyte count was 24,000 per c.mm.

Emergency bilateral thoracotomy and transverse sternotomy with median sternotomy from the suprasternal notch to the third intercostal space was performed. The pericardium was opened and both atrial appendages exposed. After systemic heparinization, $90 \mathrm{mg} . / \mathrm{m}^{2}$ body area, bypass and cooling was begun. An aneurysm of the ascending aorta, about $8 \mathrm{~cm}$. in diameter, was found. It had ruptured into the superior vena cava, the opening being about $1 \mathrm{~cm}$. in diameter. Marked venous congestion, considerable right-sided heart failure, and bilateral pleural effusions were present.

Resection of the aortic aneurysm and of the superior vena cava was performed, continuity of both vessels being restored with Teflon grafts. Profound hypothermia was used and complete cessation of circulation for several periods was necessary. At the end of the procedure the heart took over with good beat and good pressure after defibrillation, but there was considerable oozing from veins so that much time was lost in controlling the bleeding. The length of perfusion was 219 minutes.

The post-operative course was stormy, the patient never really recovering consciousness. A tracheostomy was necessary and respiration was maintained with a 

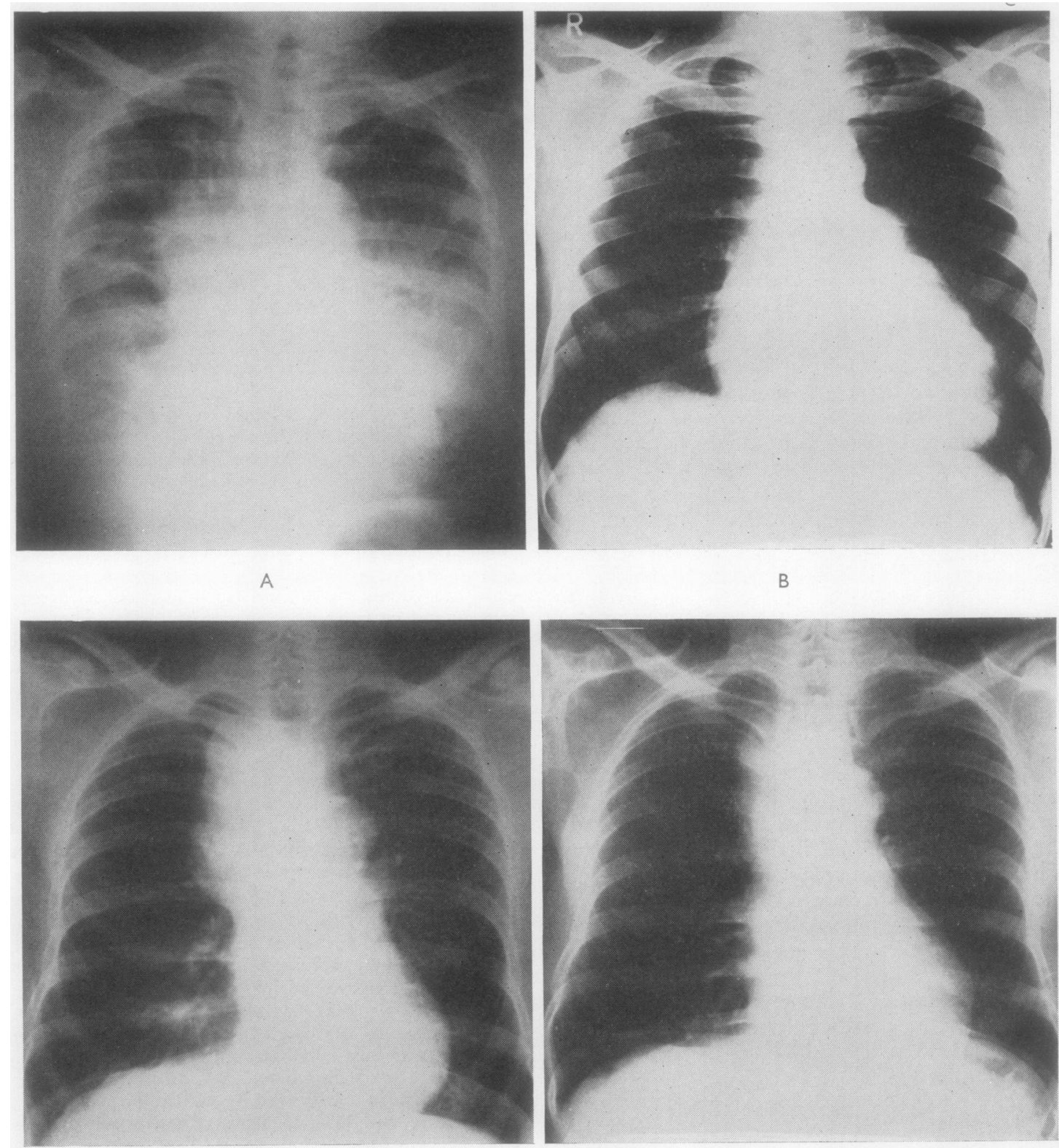

C

FIG. 1. Antero-posterior views from $(A)$ case 1 and $(B)$ case 4. (C and $D)$ Pre- and post-operative radiographs from case 3.

Bird respirator. Poor peripheral circulation, peripheral gangrene, and renal tubular necrosis developed, the patient dying two weeks after surgery. The histology showed atherosclerosis with pronounced adventitious response consistent with syphilis but equally compatible with dissection of the aorta.
Comment A man of 44 presented with an illness $\frac{\overrightarrow{0}}{\overrightarrow{0}}$ of abrupt onset resulting in superior mediastinal $\frac{O}{\square}$ compression, a fistulous murmur, and acute right $\stackrel{\circ}{\varrho}$ heart failure. The diagnosis of ruptured aortic aneurysm into the superior vena cava was confirmed $\delta$ 
at emergency surgery. The aneurysm and superior vena cava were resectable. The prolonged procedure under cardiac bypass and profound hypothermia resulted in irreversible diffuse tissue damage. Syphilis was the probable cause of the aneurysm.

CASE 2 M.M., a Bantu man of about 45 years, was admitted with a two-year story of swelling of the right chest, which progressively increased in size. Local pain began a year after the appearance of the swelling and radiated to the right arm and leg. Dyspnoea was mild, of six months' duration; dysphagia was absent. There was a story of untreated syphilis many years previously.

On examination the patient looked very ill and distressed with a large bulge, pulsating, fluctuating, and hot, the size of an orange to the right of the sternum. The swelling clearly was produced by an aneurysm eroding through the chest wall, covered only by skin and superficial tissue (Fig. 2). The pulses were all present, equal and of large volume, with a blood pressure of $130 / 60 \mathrm{~mm}$. $\mathrm{Hg}$. The apex was left ventricular in type and displaced outwards in the sixth space in the mid-axillary line. Loud murmurs of aortic incompetence were present over the front of the chest to the right and left of the sternum. The electrocardiogram showed extensive $T$ wave inversion in the left ventricular surface leads. The

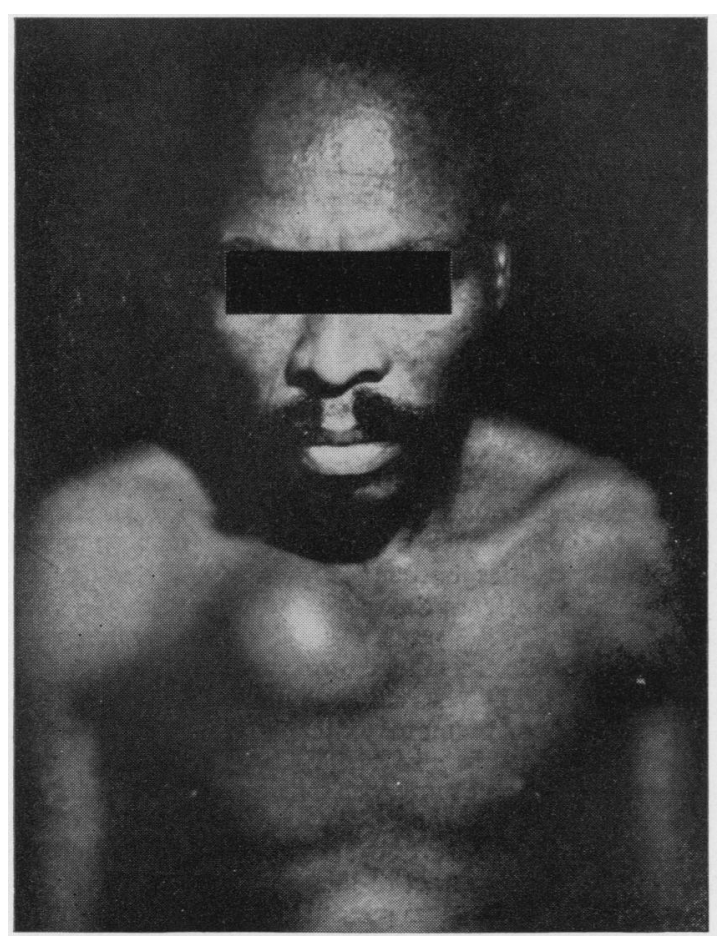

FIG. 2. Case 2. The aneurysm can be seen protruaing through the sternum and producing a swelling in the centre of the chest, covered only by the skin structures. radiological appearances were those of a diffuse aneurysm involving the ascending aorta and arch, with caraiomegaly. The serology was positive, and the erythrocyte sedimentation rate was $25 \mathrm{~mm}$./hour.

Surgery was not advised in view of the degree of aortic incompetence. However, when he deteriorated rapidly, an emergency bilateral thoracotomy was performed, with transverse sternotomy and midline splitting as in case 1 . After heparinization, cardiac bypass with profound hypothermia was begun. A large aneurysm of the arch and ascending aorta was found, with aortic incompetence. The aneurysm had eroded the second and third costal cartilages and part of the sternum. While dissecting the aneurysm it ruptured. The aorta was cross-clamped both proximal and distal to the aneurysm and a carotid artery perfused through an additional catheter. The neck of the aneurysm was resected and the excess wall removed. The aorta was reconstructed by means of a graft. The heart was defibrillated but it soon became clear that the aortic incompetence was severe. The heart was unable to maintain circulation when bypass was discontinued so that the patient died on the table after almost six hours bypass. The macroscopic appearance was that of syphilis.

Comment A desperately ill man of 45 years was admitted with aneurysm of the arch and ascending aorta, eroding through the chest and pointing under the skin. Although resection was technically possible the prolonged procedure and severe valve incompetence led to death on the table. Syphilis appeared to be the cause of the aneurysm.

CASE 3 P.P., a coloured man of 46 years, developed severe transient pain in the right upper sternal region, followed by a swelling which appeared one week before attendance at the cardiac clinic. For two years he had noticed hoarseness. He had no cardiac disability and was able to carry heavy sacks weighing $200 \mathrm{lb}$. without discomfort. Sarcoma of the sternum had been suspected.

On examination he had a small brachial pulse (blood pressure $120 / 100 \mathrm{~mm}$. $\mathrm{Hg}$ ), a diminutive right carotid pulse, collapsing left carotid, left brachial (blood pressure $160 / 80 \mathrm{~mm}$. $\mathrm{Hg}$ ), and femoral arteries. A pulsatile swelling in the right upper chest just below the clavicle, lifting up the sternum, was present. The apex beat was left ventricular, thrusting in type but not displaced. A short early diastolic murmur was audible, virtually only to the right of the sternum and in the aortic area. Elsewhere a loud aortic ejection click was present. There were no murmurs in the neck and no signs of superior mediastinal obstruction. The electrocardiogram was normal. An aneurysm of the arch and innominate artery was diagnosed, with moderate aortic incompetence. Radiological investigation (Fig. 1C) supported this diagnosis. A 10-day course of two million units penicillin daily was advised, the serology being positive.

Two months later the patient was admitted for aortography prior to surgery. The sedimentation rate was $22 \mathrm{~mm}$./hour. The aortogram (Fig. 3), done percutaneously using the Seldinger technique, showed a large saccular aneurysm of the ascending aorta near the arch 

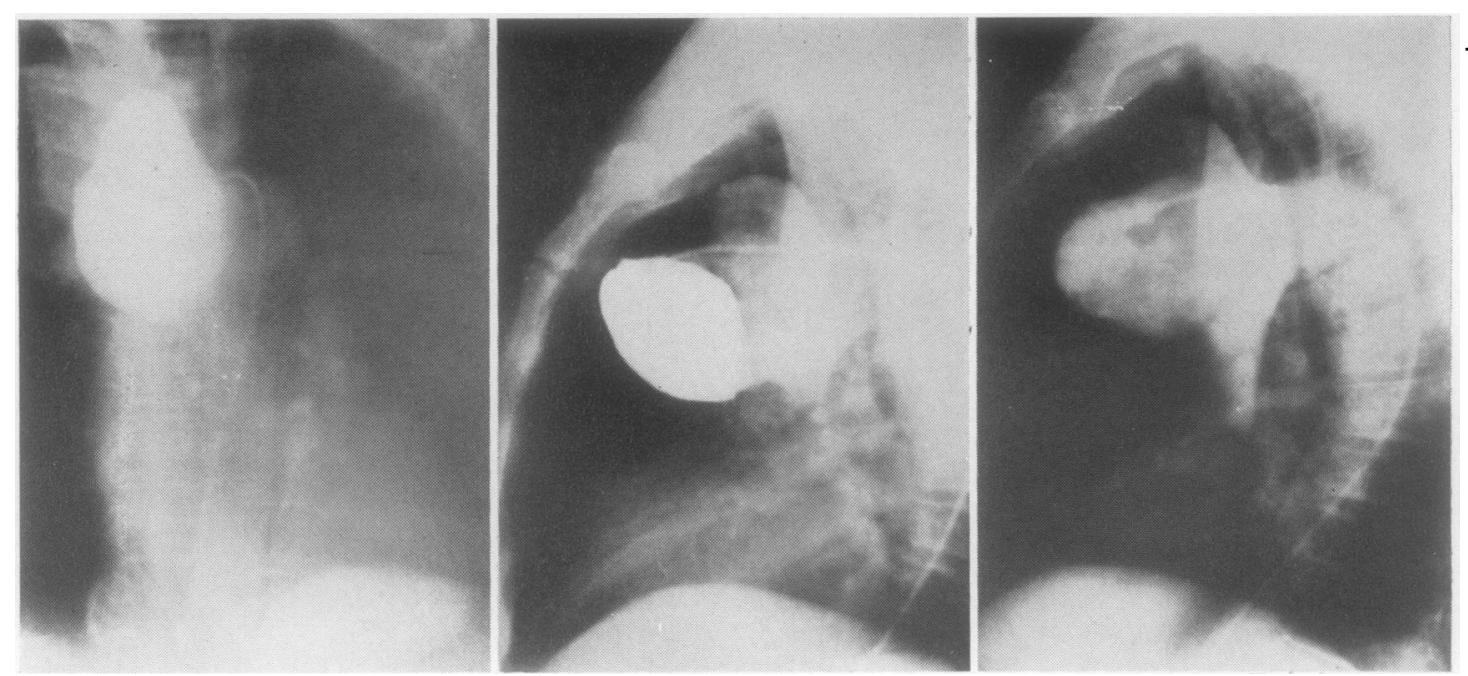

FIG. 3. Case 3. A-P and lateral angiocardiograms outlining the aneurysm of the ascending aorta which consists of a large major sac from which a second large pouch arises.

and an additional false aneurysm arising from the main sac. The three major vessels of the aorta were normally opacified distal to the aneurysm.

A bilateral thoracotomy with transverse sternotomy was performed on 14 September 1961. A saccular aneurysm of the ascending aorta and arch was found, eroding the sternum and the second and third costal cartilages on the right. No aortic incompetence was noted at operation. The innominate artery was partly thrombosed. Because of the erosion of the sternum and adherence to surrounding structures the aneurysm could not be dissected. After systemic heparinization, bypass with profound hypothermia was begun. During dissection the aneurysm ruptured. Bypass was temporarily discontinued, the brain and heart were perfused separately but circulation to the rest of the body was stopped. The neck of the aneurysm was dissected free and resected. The innominate artery was partially obliterated and the portion of the aneurysm involving this vessel was left intact. The defect in the aortic arch was reconstructed with a Teflon patch. The heart was defibrillated and immediately took over function. The duration of perfusion was 146 minutes.

The post-operative course was complicated by a right upper lobe consolidation which responded to treatment. The histology showed the condition was probably syphilitic. Six months later the patient was asymptomatic, the pulses were normal and radiography (Fig. 1D) showed marked improvement.

Comment A man of 44 years presented with an aneurysm of the ascending aorta eroding through the sternum and ribs. The aneurysm was resected successfully with complete recovery. Aortic incompotence was minimal, not being observed at surgery. Syphilis was considered to be the cause of the aneurysm.
CASE 4 D.R., a coloured man of 34 years, was well until two months before admission, apart from mild epigastric discomfort. His illness commenced acutely with upper abdominal pain followed by orthopnoea and severe effort dyspnoea. At the same time his abdomen began to swell and his neck veins stood out like cords. Generalized oedema failing to respond to treatment soon appeared.

On examination he was in congestive cardiac failure with venous distension, tricuspid incompetence, considerable hepatomegaly, and oedema. A collapsing pulse, equal in all limbs, with a blood pressure of $160 / 55 \mathrm{~mm}$. $\mathrm{Hg}$ was present. The right ventricle was enlarged with a systolic thrill in the pulmonary area and a continuous murmur at the same site. The murmur of aortic incompetence was present at the fourth left space.

The electrocardiogram showed left atrial hypertrophy and biventricular enlargement, and on screening the right $O$ atrium was markedly enlarged with pulsation of the left upper cardiac border. The radiograph (Fig. 1B) showed $\frac{D}{0}$ pulmonary oligaemia with cardiomegaly and a prominent left upper cardiac border. Cardiac catheterization and $\mathrm{N}$ angiocardiography as described elsewhere (Schrire, Beck, and Barnard, in preparation) showed aneurysmal $N$ dilatation of the ascending aorta compressing the outflow tract of the right ventricle and pulmonary artery, pro- $\sigma$ ducing extreme pulmonary stenosis. The serology was positive for syphilis.

A median sternotomy was performed and a saccular $\stackrel{\mathscr{D}}{\mathscr{D}}$ aneurysm of the root of the ascending aorta found, extending to the left and compressing the pulmonary artery and outflow tract of the right ventricle. Moderate $\frac{\vec{D}}{\Phi}$ aortic incompetence was present. The aorta was encircled with a tape, the patient was heparinized and cardiac $\stackrel{\mathbb{D}}{\stackrel{Q}{ }}$ bypass and cooling begun. The aorta was then cross- $\sigma$ clamped above the aneurysm and the pericardium packed with iced saline. After opening the aneurysm, the 
sac was resected and the incision in the aorta repaired. The heart was defibrillated and perfusion discontinued after about two hours.

The post-operative course was smooth and uninterrupted, being associated with a massive diuresis despite the marked restriction of fluids. He was discharged three weeks after surgery, completely well and with minimal signs of aortic incompetence. The histology of the aneurysm was compatible with syphilis.

Comment A coloured man of 34 years presented with acute right heart failure due to obstruction to right ventricular outflow by a syphilitic aneurysm of the ascending aorta. The aneurysm was successfully resected with immediate restoration of normal haemodynamics and cure of the patient.

CASE 5 J.A., a coloured man of 58 years, was admitted on 5 July 1961 with a four-year history of low backache. At this time he was able to work, but often the pain was so severe that he had to take to his bed for a week or two at a time. The pain was worse during the day and was aggravated by sitting for any length of time in the same position or by walking a lot. For eight months the pain had radiated to the left upper quadrant. A root pain was diagnosed and malignancy suspected. Slight effort intolerance was the only cardiac symptom present.

On examination there was no evidence of heart failure, but a disparity between the peripheral pulses and the cardiac apex was apparent. The pulses were equal and normal with a blood pressure of $120 / 80 \mathrm{~mm}$. Hg. The apex beat was thrusting in type, situated in the sixth space in the anterior axillary line, suggesting considerable left ventricular enlargement. The early diastolic murmur was also atypical, being audible to the right of the sternum and only present at the apex. An aortic ejection click was widely heard over the front of the left chest.

Radiological examination (Fig. 4A) resolved the paradox by showing marked displacement of a normal sized heart to the left by a large aneurysm of the proximal part of the descending aorta, which was eroding the vertebrae. The aortic incompetence was thought to have little haemodynamic significance. Retrograde aortography (Fig. 5) through the right brachial artery revealed a saccular aneurysm of the descending thoracic aorta with mild aortic regurgitation. The electrocardiogram showed $U$ wave inversion over the left ventricle as the only abnormality. The serology was positive for syphilis.

Elective surgery using a left thoracotomy through the bed of the sixth rib was performed. After heparinization a left atrial/left femoral artery bypass was established. An aneurysm of the descending thoracic aorta, about $12 \mathrm{~cm}$. in diameter, extending from just above the diaphragm to immediately below the ligamentum arteriosum, was found. It extended into the left lung behind the heart and had eroded three vertebrae. There was a large blood clot in the aneurysm. The aneurysm was partially resected and the remainder of the sac closed. Aortic continuity was restored with a Teflon graft. The length of perfusion was 180 minutes.

The post-operative course was uneventful, the patient being discharged well three weeks after surgery. The histology showed laminated blood clot but no recognizable wall. Nine months later he was asymptomatic and back at work.

Comment An aneurysm of the proximal portion of the descending aorta, eroding the vertebrae and producing severe back and root pain, in a coloured man of 58. The aneurysm displaced the heart to the left, producing apparent cardiomegaly, only slight aortic incompetence being present. Successful excision of the aneurysm with cure was achieved. Syphilis was the most probable cause.

CASE 6 A.B., a coloured man of 38 years, was admitted in May 1956 for surgical repair of a subacute perforated peptic ulcer. There were no cardiac symptoms at the time; the heart was normal in size, but a blood pressure of $160 / 70 \mathrm{~mm}$. $\mathrm{Hg}$ was found in the right arm and the murmurs of aortic incompetence were heard. Radiologically an aortic aneurysm was present. The electrocardiogram was normal. A course of penicillin therapy was given, the serology being positive for syphilis.

In 1960 he had to stop working because of effort dyspnoea which progressed but never to the stage of orthopnoea or paroxysmal cardiac dyspnoea. Early in February 1962 he had a small haemoptysis and a few days before admission he coughed up 'about a gallon' of blood. Thereafter the cough continued with bloodstreaking of the sputum.

On examination moderate aortic incompetence was present with a 'drum-like' second sound, the murmurs and altered $A 2$ being best heard to the right of the sternum. The blood pressure in the right arm was $155 / 70 \mathrm{~mm}$. Hg and in the left $140 / 60 \mathrm{~mm}$. Hg. The electrocardiogram was normal and a radiograph showed a large aneurysm with calcification of the wall of the sac (Fig. 4B). During the following week he had three more haemoptyses, a 'basin-full' at a time, and steadily deteriorated, losing $11 \mathrm{lb}$. (4.99 kg.) in weight.

He was admitted for study and had a haemoglobin of $10 \mathrm{~g} .100 \mathrm{ml}$. Retrograde arterial catheterization of the right brachial artery was performed and dye was injected into the ascending aorta. Moderate aortic incompetence was present, with dilated aortic sinuses and normal coronary arteries. A saccular aneurysm of the aorta was shown, involving the descending aorta just beyond the left subclavian artery, extending posteriorly and laterally (Fig. 6). Four hours after this procedure the patient had another haemoptysis, which he regarded as no more than usual, and on measurement he was found to have lost $2,000 \mathrm{ml}$. blood. Transfusion was immediately begun and he was referred for emergency surgery.

A left thoracotomy through the bed of the fourth rib was performed. The segment of the aorta immediately proximal to the aneurysm was dissected free and encircled with a tape. A left atrial/left femoral artery bypass with moderate hypothermia was started after heparinization, since the aneurysm was torn while attempting to dissect it free from the left lung. The aneurysm involved the descending aorta immediately below the origin of the 

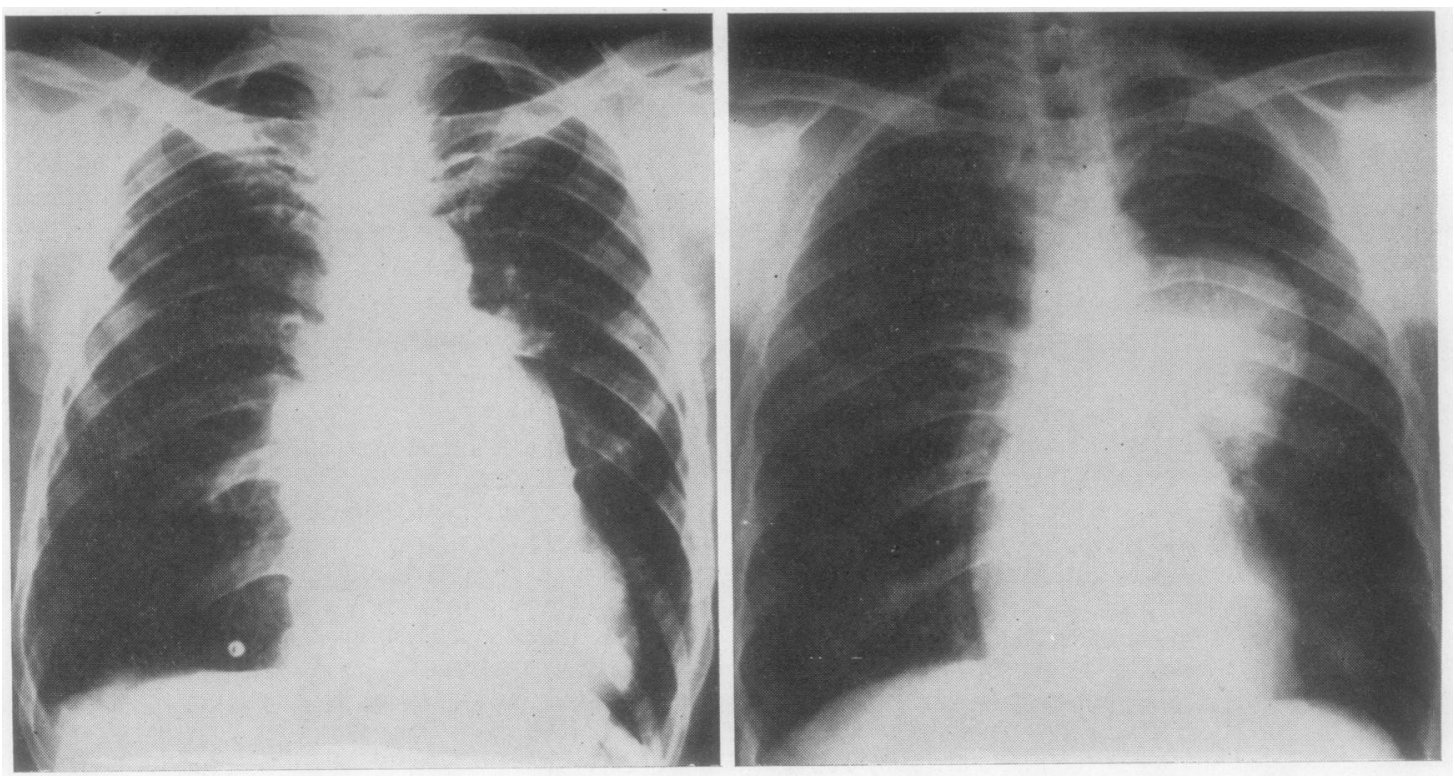

A
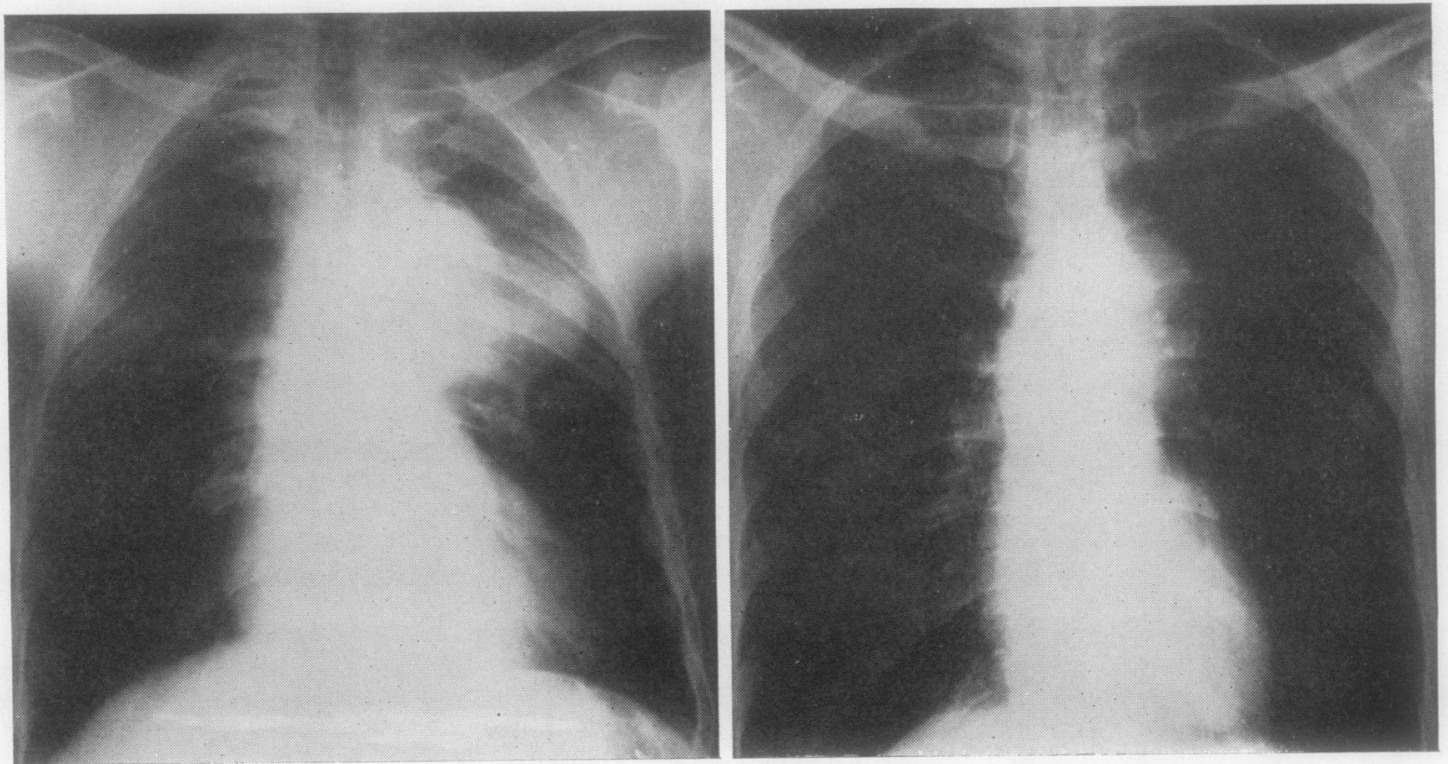

C

D

FIG. 4. Antero-posterior views from $(A)$ case $5,(B)$ case $6,(C)$ case 7 , and $(D)$ case 8 .

left subclavian artery. It was about $12 \mathrm{~cm}$. long and $9 \mathrm{~cm}$. in diameter. The left lung was adherent over the aneurysm and at one point the aneurysm had actually ruptured into the lung. The aneurysm was resected and continuity of the aorta restored by a Tefion graft. The procedure took 223 minutes.
Immediately after surgery the chest had to be re-opened to control a massive haemorrhage from an intercostal vessel.

The post-operative course was stormy. From the $\bar{\sigma}$ cerebral point of view, the patient came round from the anaesthesia satisfactorily. Tracheotomy with assisted 
FIG. 5. Case 5. A-P and lateral angiograms showing the large, saccular aneurysm of the descending aorta eroding the vertebrae and displacing the heart forwards and to the left.

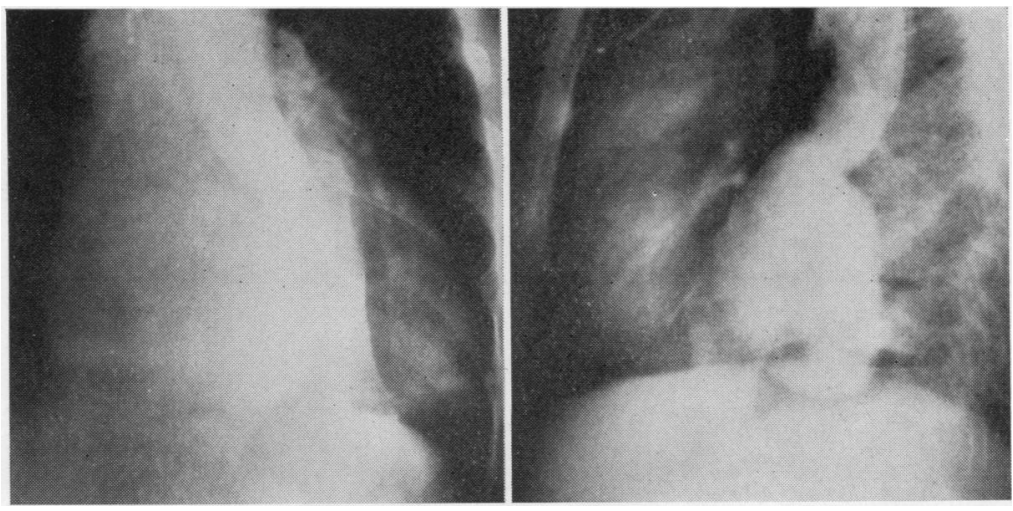

FIG. 6. Case 6. A-P and lateral angiograms showing the large, saccular aneurysm of the descending aorta with partial extravasation of the dye beyond the sac. The aneurysm is eroding the left lung and moderate aortic incompetence is present.
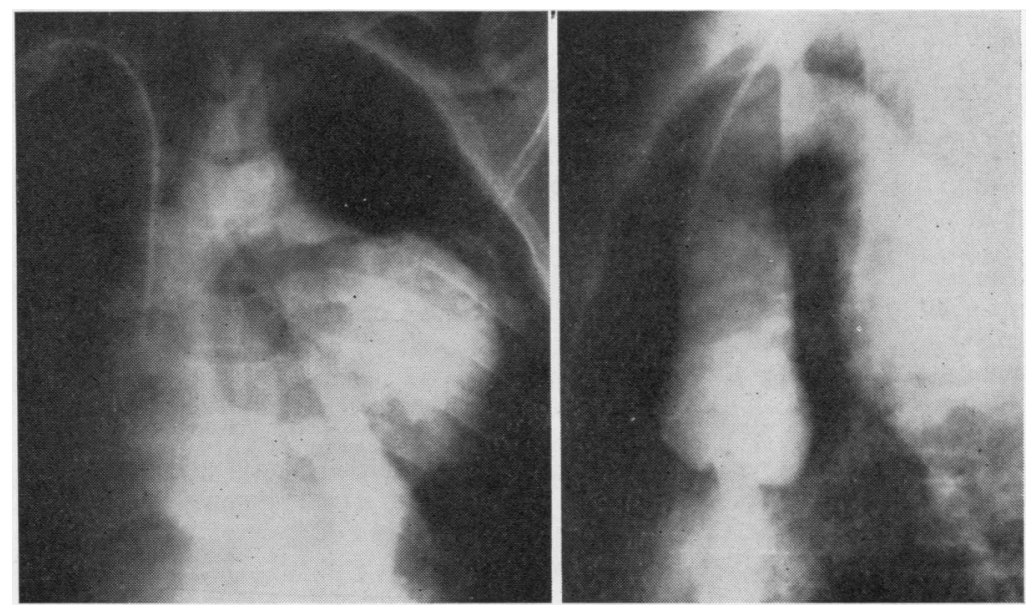

respiration became necessary two days later because of pulmonary complications, due to the pre-operative haemoptyses. Oliguria and renal shut-down then developed. The usual regime of restricted fluids and reduced caloric intake was introduced, and the patient appeared to be making good progress. On the fifth day postoperatively the serum potassium had risen and oral resins were introduced, although the patient seemed to be making good progress and was perfectly satisfactory from the haemodynamic and circulatory points of view. Insulin, in doses of 2.5 units at two to three-hourly intervals for six doses over 15 hours, was given. During the early hours of the morning the patient became comatose and could not be roused. After 50\% dextrose he promptly regained consciousness and was completely rational. Two hours later he again lapsed into coma and died before help could be obtained. At necropsy the pituitary and other endocrine glands appeared to be normal, the aneurysm had been satisfactorily repaired and the kidneys showed the changes of acute tubular necrosis in the stage of regeneration. The histology of the aorta showed a moderate degree of atherosclerosis and features consistent with syphilis.
Comment A coloured man of 38 years presented with repeated massive haemoptyses due to an aneurysm of the proximal descending aorta rupturing into the left lung. Minimal aortic incompetence was present. Emergency resection of the aneurysm was successful but the post-operative period was stormy due to pulmonary and renal complications. The patient died, apparently from hypoglycaemic coma due to excessive sensitivity to insulin.

CASE 7 K.S., a coloured man of 59 years, had no complaints until February 1962, when he suddenly had a haemoptysis, coughing up about $500 \mathrm{ml}$. of blood. A week later he coughed up twice as much blood. He was admitted elsewhere, found to have radiological evidence of aortic aneurysm (Fig. 4C) with a 'collapse' of the left upper lobe, and was referred to the cardiac clinic. On examination there were no abnormal findings except for the altered quality of the aortic second sound, which was tambour-like, especially to the right of the sternum. There was no tracheal tug. The blood pressure in both arms was $140 / 85 \mathrm{~mm}$. $\mathrm{Hg}$ and the electrocardiogram was 

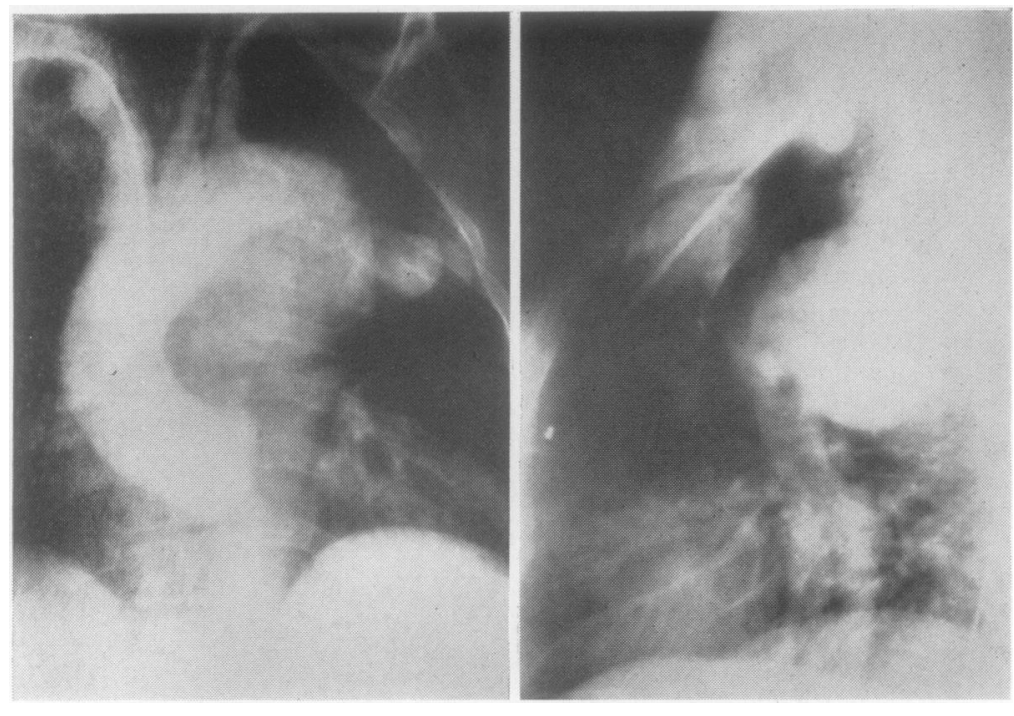

FIG. 7. Case 7. A-P and lateral angiograms showing the aneurysm of the descending aorta with a small 'daughter' aneurysm protruding from the main sac into the left lung. The ectatic innominate artery is outlined. normal. The serology was positive for syphilis and penicillin therapy was given.

The patient was admitted for retrograde catheterization, and a large saccular aneurysm with a slight pedicle attached to the descending aorta, below the origin of the left subclavian, was demonstrated, with a smaller false aneurysm lateral to the primary aneurysm (Fig. 7). Ectasia of the right innominate artery was noted, but there was no aortic incompetence.

While awaiting surgery the patient had several further large haemoptyses, making surgical intervention urgent. On 15 March 1962 a left thoracotomy through the bed of the fifth rib was performed, and the aorta encircled with a tape proximal and distal to the aneurysm. The aneurysm was about $10 \mathrm{~cm}$. in diameter, starting immediately below the left subclavian and extending about $14 \mathrm{~cm}$. to about $4 \mathrm{~cm}$. above the diaphragm. The aneurysm had eroded three of the thoracic vertebral bodies and also extended into the left lung.

After heparinization, a left atrial/left femoral artery bypass under moderate hypothermia was begun. The aneurysm was partially resected, the sac which had burrowed into the lung being left behind and oversewn. Aortic continuity was restored by insertion of a Teflon graft. The perfusion time was 157 minutes.

Post-operatively the patient gave no trouble and made a smooth recovery. Histological examination of the aortic aneurysm specimen showed laminated thrombus and degenerative changes but no recognizable arterial wall structure. Syphilis was suggested as the cause, although a dissecting aneurysm or arteriosclerosis could not be excluded.

Comment A coloured man of 59 presented with repeated massive haemoptyses due to an aneurysm of the proximal descending aorta eroding into the left lung and vertebrae. Successful excision of the aneurysm with complete recovery was achieved.
Aortic incompetence was absent. Syphilis is suggested as the most likely cause.

CASE 8 W.E., a coloured man of 61 years, complained of stabbing intermittent pain in the back between the scapulae, worse on lying down, for seven years. For three years the pain had radiated down both arms, which felt numb and paraesthetic. Numbness of the right arm was aggravated by lying on the right side and the left arm was affected when he lay on the left. All the fingers became affected but not the thumbs. He subsequently developed pain in both sides of the chest, similar to the back pain, unrelated to effort and not relieved by rest. For one year he experienced lower backache on standing, associated with a cramp-like pain in the thighs and calves, relieved by exercise. In 1954 the Wassermann reaction was doubtful and the Kahn positive. In 1961 these tests were negative.

On examination all pulses were equal and the blood pressure was $130 / 90 \mathrm{~mm}$. Hg. There was no cardiomegaly and no heart murmurs. The electrocardiogram was normal. Radiological examination showed a dilated aortic knuckle with a rim of calcification (Fig. 4D) and in the lateral view erosion of the dorsal vertebrae could be seen.

Retrograde angiographic investigation through the right brachial artery with injection of dye into the ascending aorta showed a fusiform aneurysm of the aorta just below the left subclavian (Fig. 8). There appeared to be clot in the aneurysm. No aortic incompetence was present. Surgical excision was advised.

On 22 March 1962 left thoracotomy through the bed of the fifth rib was performed. The aneurysm was encircled with cotton tape above and below, and after heparinization a left atrial/left femoral artery bypass with moderate hypothermia was commenced. The aneurysm extended for about $10 \mathrm{~cm}$. below the left subclavian, the diameter being about $6 \mathrm{~cm}$. There was 
FIG. 8. Case 8. A-P and lateral angiograms showing a fusiform aneurysm involving the proximal part of the descending aorta and eroding the vertebrae.
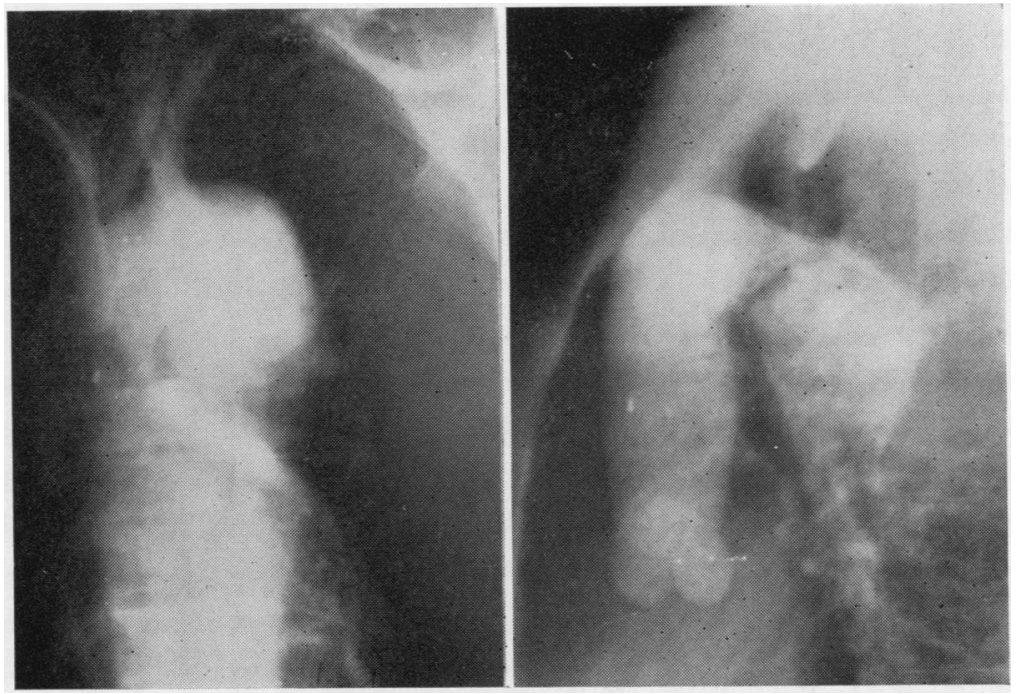

slight erosion of three of the thoracic vertebral bodies. The aneurysm was resected and aortic continuity restored by means of a Teflon graft. The duration of bypass was 125 minutes. There was some oozing from the chest wall adhesions, which gave rise post-operatively to an effusion, but apart from this recovery was smooth. Back pain immediately disappeared. Histological examination of the aneurysm showed calcification at one end and the features of atherosclerosis.

Comment A coloured man of 61 years presented with root pain due to an aneurysm of the proximal descending aorta eroding three thoracic vertebrae. Successful excision of the aneurysm with complete recovery was achieved. Aortic incompetence was absent. Syphilis or arteriosclerosis could be regarded as the probable cause of the aneurysm.

\section{DISCUSSION}

Aneurysm of the thoracic aorta, particularly that of the ascending aorta, is usually syphilitic in origin. Whereas this condition is becoming infrequent in western countries, in South Africa and the developing areas it still presents a major and formidable complication of the disease. In this series it was probably responsible for the process in seven of the eight patients.

The disease produces its effects by compression and erosion of neighbouring structures, often resulting in perforation or massive haemorrhage. Most of the common and uncommon complications of the disease are exemplified in this small series of patients. Thus the clinical presentation was that of superior mediastinal compression, arteriovenous fistula formation, erosion of the sternum, ribs, and vertebrae, massive haemoptysis, and obstruction to the pulmonary artery.

Involvement of the aortic valves is common and aortic incompetence of varying degrees was present in four of the eight patients. In the presence of haemodynamically significant aortic incompetence, surgical repair of the aneurysm alone may be insufficient. Radiological and angiographic investigation is helpful in the localization of the lesion and outlining the disturbed anatomy. Retrograde arteriography, either by the percutaneous route or by direct exposure of a vessel with injection of radio-opaque material $(70 \%$ Hypaque in our patients) and bi-plane radiography, gave satisfactory results.

The indications for surgery were clear-cut in all the patients. The aneurysm was either an immediate threat to life, producing compression of vital structures or massive haemorrhage, or was responsible for intractable vertebral or root pain.

Despite the remarkable advances in cardiovascular surgery, the treatment of aneurysm of the thoracic aorta remains a difficult problem. Treatments such as ligation (Gordon-Taylor, 1950; Greenough, 1929; Lane and Peirce, 1951; Lilienthal, 1915; Matas, 1914 ; Rundle, 1937; Shumacker, 1947), the introduction of foreign material to promote clotting (Colt, 1927; Corradi, 1914; Moore and Murchison, 1864), wrapping to stimulate peri-arterial fibrosis (Abbott, 1949; Cowley, Sloan, and Sullenberger, 1951; De Takats and Reynolds, 1947; Middleman and Drey, 1951 ; Harrison and Chandy, 1943 ; Page, 1939; Pearse, 1940; Poppe, 1948; Poppe and De Oliveira, 1946; Yeager and Cowley, 1948), and 
endo-aneurysmorrhaphy (Matas, 1888) have largely been abandoned. It is generally agreed that excision of the aneurysm with restoration of normal blood flow is the most effective method of surgical treatment.

The success of this radical approach depends largely on six factors, namely adequate exposure, control of the circulation through the aneurysm, prevention of tissue damage, restoration of normal blood flow after resection, meticulous attention to haemostasis, and prevention of infection.

EXPOSURE The difficulty of finding a single adequate approach to the ascending aorta, arch, and descending aorta lies in the fact that the arch does not only pass from right to left, but also from in front at the manubrium backwards to the level of the fourth thoracic vertebra. The ascending aorta and the beginning of the arch are thus better exposed through an anterior incision, whereas the distal portion of the arch and the descending aorta are better approached through a posterior incision.

Bardenheuer (1885), Kocher (1911), and Sauerbruch and Schumacker (1911) described an approach to the anterior mediastinum. Milton (1901) described the longitudinal splitting approach to the anterior mediastinum and this was subsequently used by Lilienthal (1915), Dunhill (1922), and $\underset{\vec{\rho}}{\stackrel{P}{9}}$ Churchill, Sweet, Soutter, and Scannell (1950). The $\overline{0}$ exposure of the blood vessels in the superior anterior mediastinum has been fully described by Shumacker (1948), Elkin (1945, 1946), and Wilson and Carr $\mathbb{\otimes}$ (1948).

It has been the general experience that the best exposure of the ascending aorta and proximal $\vec{\circ}$ portion of the arch is the vertical sternal-splitting $\overrightarrow{\vec{C}}$ incision. If the aneurysm is unusually large, with ${ }_{0}$ erosion of the chest wall (Fig. 2), vertical splitting $\overrightarrow{\vec{z}}$ of the sternum is dangerous until the circulation? through the aneurysm has been controlled. In such $\infty$ patients a right anterior thoracotomy for circulatory control is performed first, and the incision is then 오 extended. Either a median sternotomy extending 0 cephalad, a transverse sternotomy or a combination of the two, will give adequate exposure.

In four of our patients the aneurysm either involved the ascending aorta, the ascending aorta and arch, or the arch alone (Table 1 ). In cases 1 and $2 \%$ a bilateral thoracotomy through the bed of the $\omega$ fourth rib and a median sternotomy combined with a vertical sternotomy was used for exposure. In case 3 a bilateral thoracotomy with transverse sternotomy, and in case 4 a vertical sternotomy alone, proved safe and gave adequate exposure.

TABLE I

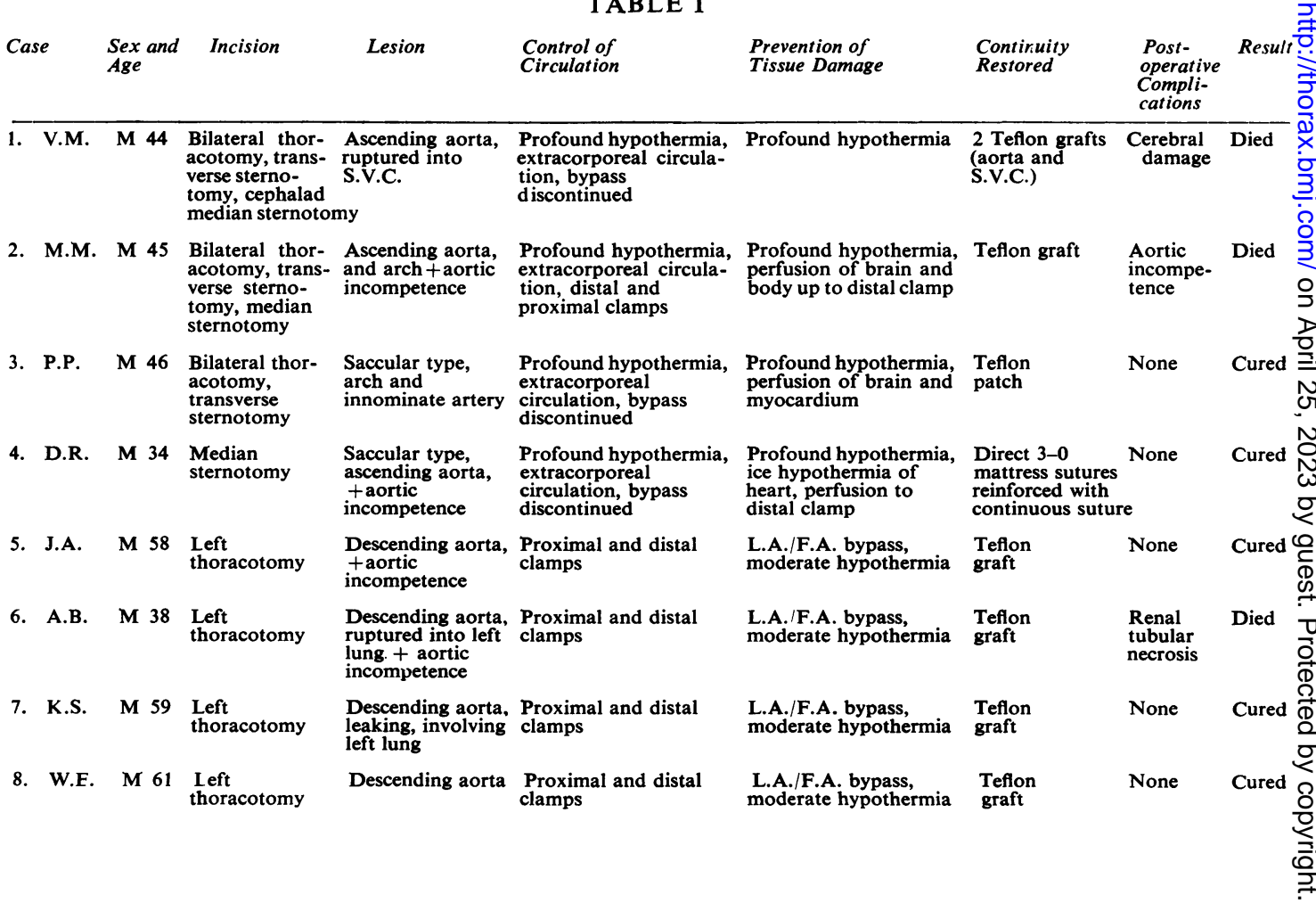


Aneurysm of the descending thoracic aorta and distal arch is best approached through a left posterolateral thoracotomy, the interspace depending on the level of the lesion. This incision was used in cases 5 to 8 . The distal arch and upper descending aorta are best exposed through the third interspace, the middle of the descending aorta through the fourth or fifth interspaces, and the lower portion of the descending aorta through the sixth interspace. When the descending thoracic aorta is extensively involved, two separate intercostal or rib bed incisions may be necessary.

CONTROL OF CIRCULATION THROUGH THE ANEURYSM Before any aneurysm can be excised, the circulation of blood through the sac must be stopped. This can be achieved by (a) clamping the neck of the aneurysm, (b) isolating the involved segment of the aorta, or (c) stopping the heart and entire circulation at low body temperatures.

(a) Clamping the neck of the aneurysm This procedure is only possible in a saccular aneurysm (Bahnson, 1953) with a fairly narrow neck, and even then may be dangerous. Before a clamp can be applied across the mouth of the sac the area must be carefully dissected and the surgeon runs the risk of entering the sac before bleeding can be adequately controlled. When applying the clamp, difficulty may be encountered in positioning it in such a way that the entire sac can be excised without encroaching on the lumen of the parent vessel. There is always the possibility that a clot or a piece of calcium may break off to form an embolus as the clamp is applied. In bigger saccular aneurysms it is much safer to use other means of controlling the circulation through the sac before it is excised.

In this series two patients (cases 4 and 5) had a saccular aneurysm of the ascending thoracic aorta. In both, dissection and clamping the neck of the aneurysm would have been too hazardous a procedure, thus in this series this method of control was never used.

(b) Isolation of the involved segment of the aorta This entails clamping the aorta above and below the aneurysm and also any patent branches leaving the segment, with resultant temporary interruption of blood flow distal to the clamps. Whereas occlusion of abdominal aorta may be tolerated for periods of two or more hours without ill effect, occlusion of the thoracic aorta is not tolerated for any length of time. The extent of the damage produced by this procedure depends on the level of occlusion; the control of this factor will be discussed later.

(c) Stopping the heart and circulation At profound levels of hypothermia the entire circulation may be stopped. In our experience this has proved to be a useful technique in the resection of large aneurysms, where dissection is difficult and dangerous. Profound hypothermia is induced in these patients by using the bubble oxygenator and Benington heat exchange unit (Terblanche and Barnard, 1960; Barnard, Terblanche and Ozinsky, 1961). When the midoesophageal temperature drops to approximately $10^{\circ} \mathrm{C}$. bypass is discontinued. The sac is opened and its boundaries can be identified. The aortic lumen distal and proximal to the aneurysm and any major branches leaving this segment can be isolated. The bypass is then re-arranged to supply as much of the body as possible, which will be described later. In this series, cessation of circulation was necessary in three patients (cases 1, 3, and 4).

PREVENTION OF TISSUE DAMAGE In occluding the thoracic aorta, ill effects may be caused both proximal and distal to the site of the clamp. The severity of the damage depends on the proximity of the clamp to the heart, thus a clamp on the ascending aorta will immediately result in cardiac strain proximally and in severe ischaemic damage to the brain distally. On the other hand, a clamp on the descending aorta may be tolerated for up to 30 minutes without proximal or distal ill effect. However, it is wise to take special precautions at all levels in thoracic aortic clamping.

Descending thoracic aorta Temporary arrest of the circulation through a segment of the descending thoracic aorta can increase the vascular resistance of the heart and may result in ischaemic damage to the spinal cord and, less frequently, to the kidneys, liver, and bowel. For the successful resection of an aneurysm in this area these factors must be controlled, especially spinal cord damage. This has been achieved by several means, viz., hypothermia (Cooley and DeBakey, 1956a ; Pontius, Brockman, Hardy, Cooley, and DeBakey, 1954 ; Pontius, Bloodwell, Cooley and DeBakey, 1955 ; Lam and Aram, 1951 ; Mahorner and Spencer, 1954 ; Clatworthy and Varco, 1950 ; Schafer and Hardin, 1952), left atrial/femoral arterial bypass (Cooley, DeBakey, and Morris, 1957; Gerbode, Braimbridge, Osborn, Hood, and French, 1957), and left atrial/ femoral arterial bypass with hypothermia (Fig. 9).

In the four patients in this series who had aneurysms of the descending thoracic aorta (Table I), a left atrial/left femoral artery bypass plus moderate hypothermia $\left(32^{\circ} \mathrm{C}\right.$.) was used with satisfactory results (Fig. 9). The occlusion time varied between 125 and 223 minutes. None of the patients showed evidence of proximal damage and only one showed evidence of distal damage, viz., 


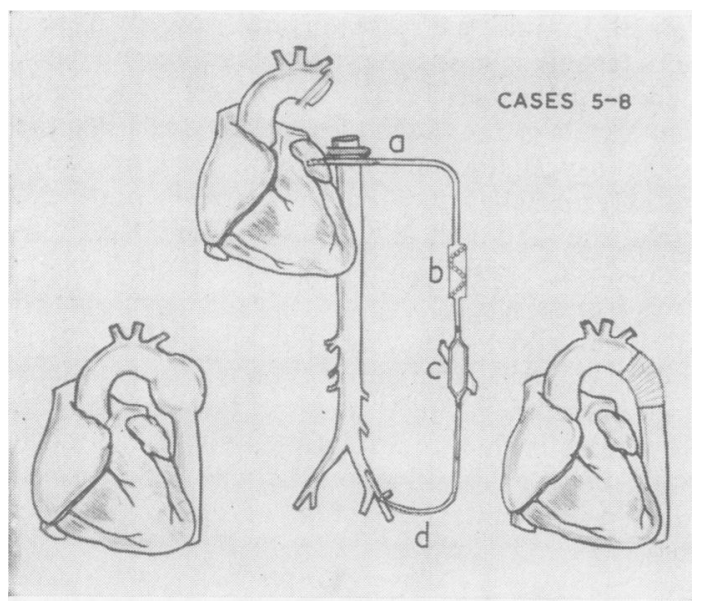

FIG. 9. Cases 5 to 8. Method of treatment of aneurysm of the descending thoracic aorta using left atrial/femoral artery bypass with moderate hypothermia. $a=$ Catheter in left atrium; $b=$ Sigmamotor pump; $c=$ Benington heat exchanger; $d=$ catheter in femoral artery.

the picture of renal tubular necrosis (case 6). This patient, with a rupture of the aneurysm into the lung and severe haemoptyses before and during surgery, had periods of severe hypotension and a large amount of blood in the lungs. Both features may have resulted in renal damage. There were no patients with spinal cord damage after surgery.

When the aneurysm is large, bypass and cooling is started before dissection of the aneurysm, as the drop in pressure in the aorta lessens the danger of rupturing the aneurysm when it is handled and facilitates dissection. Further, if necessary, clamps may be applied to the aorta at any stage, once bypass is in progress.

Ascending thoracic aorta When the aneurysm involves the distal portion of the ascending aorta, thus allowing a clamp to be applied proximal to the aneurysm without interfering with coronary blood supply, a temporary bypass can be used (DeBakey, Cooley, Crawford, and Morris, 1958). When the proximal part of the ascending aorta is involved, total cardiac bypass is necessary (Cooley and DeBakey, 1956b ; Cooley et al., 1957). The myocardium may be protected from anoxic damage by coronary artery perfusion or by local hypothermia with iced saline.

In case 4 in this series, the aneurysm involved the proximal ascending aorta (Fig. 10), and in case 1 the proximal aorta was also involved but, in addition, it had ruptured into the superior vena cava (Fig. 11). Cardiopulmonary bypass with profound hypothermia was used in both cases (Table I). In case 4, the involved portion of the aorta was isolated with clamps, perfusion was continued, and the heart was protected by packing it with iced saline (Fig. 10). In case 1 , due to the fistula into the superior vena cava, the perfusion could only be recommenced and bypass continued when the repair had been effected.

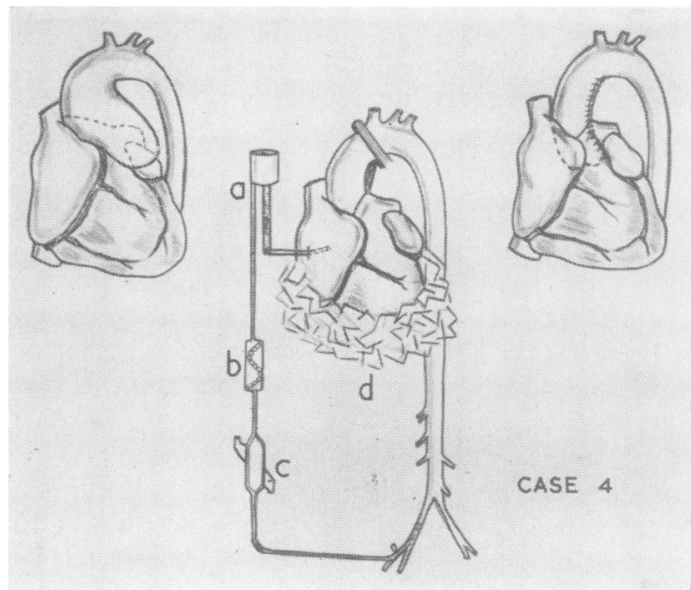

FIG. 10. Case 4. Aneurysm of the ascending aorta involving the aortic valve ring. Cardiopulmonary bypass, profound hypothermia, and ice arrest of the heart were employed, and perfusion of the body up to the distal clamp continued. Direct suture repair of the aorta to narrow the aortic valve ring, thus restoring aortic competence. $a=$ Bubble vxygenator; $b=$ Sigmamotor pump; $c=$ Benington heat exchanger; $d=$ iced saline chips around the heart.

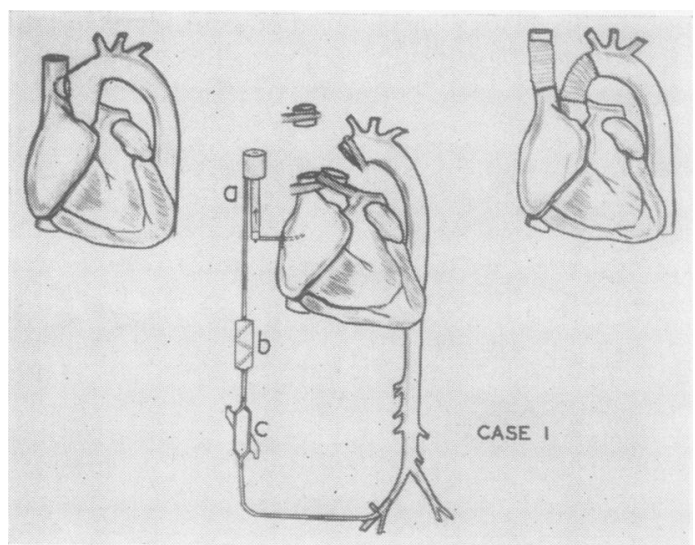

FIG. 11. Case 1. Aneurysm of the ascending aorta which ruptured into the superior vena cava. Cardiopulmonary bypass with profound hypothermia and circulatory arrest, during the period when the superior vena cava was repaired, were employed. $a=$ Bubble oxygenator; $b=$ Sigmamotor pump; $c=$ Benington heat exchanger. 
When the proximal aorta is involved, aortic incompetence is often present. In such cases the leak from this valve must be repaired and a left ventricular vent used, otherwise it may be difficult to restart the heart or to maintain an adequate cardiac output after surgery-see case 2 (Table I).

Arch aneurysm Successful excisional therapy of an aneurysm involving this important section of the thoracic aorta has been achieved by using temporary shunts from the ascending aorta to the descending aorta and the cerebral vessels (DeBakey et al., 1958). This method is cumbersome and the technique of choice is controlled extracorporeal circulation (Cooley et al., 1957). During the period when the aortic arch is isolated from the circulation, the brain must be supplied with a separate arterial line.

We preferred to use extracorporeal circulation with profound hypothermia, and in two patients (cases 2 and 3) in whom the aortic arch was involved this technique was used (Table I). As already mentioned, there is the advantage that flow through the sac can be discontinued by stopping the bypass. Even at these low temperatures, however, it is dangerous to deprive the brain, and to a lesser extent the heart, of oxygen for longer than 30 minutes. In case 1 (Fig. 11), in whom the superior vena cava also had to be repaired with a graft, it was necessary to stop the circulation for 55 minutes, and irreversible cerebral damage resulted (Table I).

In case 2 (Fig. 12) the brain was perfused separately but the myocardium was not protected. The aortic incompetence was also not repaired and, although

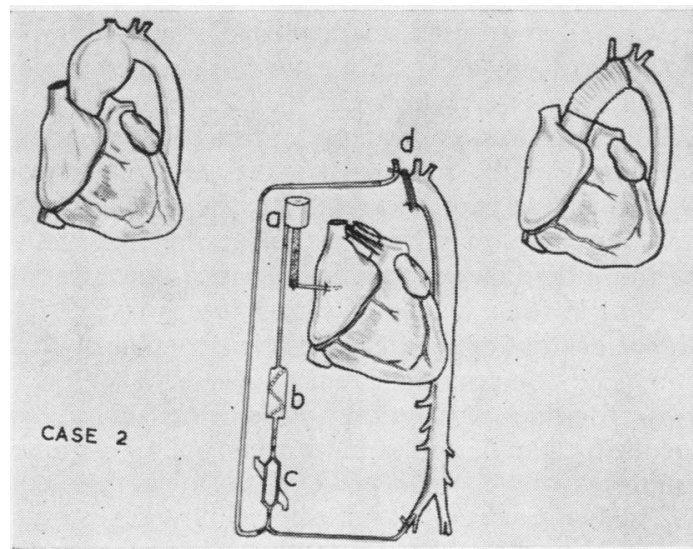

FIG. 12. Case 2. Fusiform aneurysm of the ascending aorta and arch. Cardiopulmonary bypass with profound hypothermia and perfusion of the brain and the body up to the distal clamp were used. Continuity of the aorta was restored with a tube graft to which the innominate artery was anastomosed. $a=B$ Bbble oxygenator; $b=$ Sigmamotor pump; $c=$ Benington heat exchanger; $d=$ distal clamp.

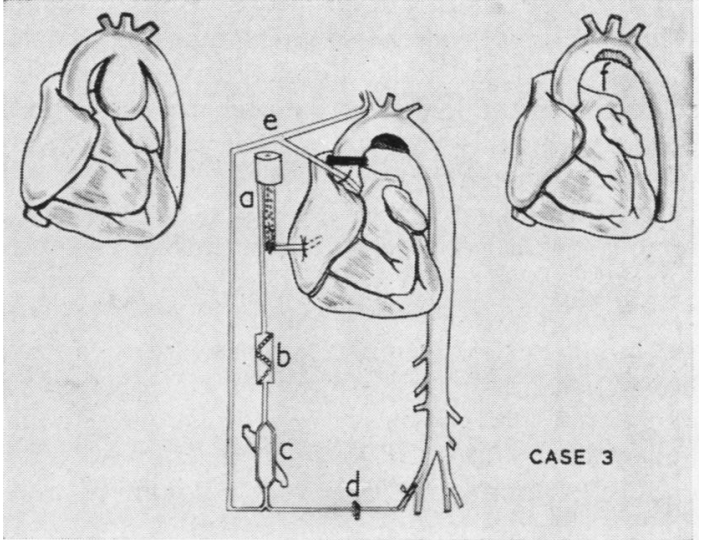

FIG. 13. Case 3. Saccular aneurysm of the ascending aorta and arch. Cardiopulmonary bypass with profound hypothermia was used. As a distal clamp could not be applied, the femoral artery line was clamped (d) and onlv the coronaries and brain were perfused. Once the aneurysm was resected, the defect in the aorta was repaired with a Teflon patch (f). $a=$ Bubble oxygenator; $b=$ Sigmamotor pump; $c=$ Benington heat exchanger; $d=$ clamp on femoral line; $e=$ art erial supply to brain and coronaries; $f=T e f l o n$ patch repair.

the heart restarted after the procedure, a good systemic pressure could not be maintained (Table I).

In case 3 it was not possible to apply a clamp distal to the aneurysm (Fig. 13). Bypass was begun and profound hypothermia was induced. When the desired temperature had been reached, the bypass was discontinued, the sac was opened, and the limits of the aneurysm were identified. Using a second arterial line, the brain and myocardium were now perfused, the remainder of the body being without a blood supply for 65 minutes while the aneurysm was excised and the aorta repaired. The postoperative course was uneventful.

At these low temperatures only one of the arteries to the brain need be supplied with blood. It is sufficient, therefore, to supply either one vertebral (through the subclavian) or one carotid artery.

RESTORATION OF NORMAL BLOOD FLOW AFTER RESECTION When aneurysms are treated by excision, it is important that the entire sac is detached from the parent vessel so that, when normal blood flow is restored, the sutures will not pass through a vessel wall weakened by aneurysmal dilatation.

In saccular aneurysms, where the neck of the sac is small, blood flow can be restored by direct suture of the mouth of the sac (case 4, Fig. 10; Table I). When the aortic wall is diseased, it is safer to close the mouth with interrupted sutures tied over plastic 
pillows to prevent the sutures from cutting through. When the mouth of the saccular aneurysm is large (case 3, Fig. 13 ; Table I), direct suture closure may encroach on the lumen of the parent vessel, and in these patients it is better to close the defect by means of a plastic patch.

In fusiform aneurysms, excision of the sac means removal of a segment of the aorta, thus flow can only be restored by the insertion of a tube graft (cases 1, 2, and 5 to 8 ; Figs. 9, 11, and 12 ; Table I).

Synthetic arterial substitutes have largely replaced homografts in surgery of the thoracic aorta, as the danger of thrombosis is small in a graft with a lumen the size of the thoracic aorta. Woven Dacron and Teflon grafts are most widely employed today and, in this series, woven crimped Teflon grafts were sutured in place using a continuous over-andover 4-0 silk suture. Branches may be attached to the graft by cutting a suitable sized hole and anastomosing the branch to the graft at this point (case 2, Fig. 12).

METICULOUS ATteNiION to haEMostasis A large number of the failures of cardiovascular surgery may be attributed to excessive bleeding in the postoperative period. This applies particularly to the treatment of thoracic aortic aneurysm, where the exposure is extensive, heparin is used routinely, and large areas are dissected, leaving raw bleeding surfaces.

In order to minimize the dangers of post-operative haemorrhage, bleeding points must be controlled during the exposure, the anastomoses must be carefully completed without unnecessary trauma to the vessel wall, and raw bleeding surfaces should be covered when possible. These troublesome raw areas are encountered particularly where adherent sac segments of the aneurysm are dissected away, especially where bone has been eroded. We have therefore adopted the policy of not excising the sac over these areas but rather of cleaning out all the clot and fibrin, and then oversewing these segments of the sac, instilling a wide-spectrum antibiotic. The danger of infection in a piece of aneurysmal wall left behind is not as great as was believed (Gaertner, Spencer, and Bahnson, 1962) and, in our experience, there has been no trouble using this method.

PREVENTION OF INFECTION Infection is a danger in any surgery. When plastic prostheses are used, infection often leads to the death of the patient. It is therefore important to introduce as few organisms as possible during surgery, not to leave a culture medium in which organisms may multiply and, finally, to kill off any organisms that may be present.
Apart from the usual sterile precautions taken in $\underset{\vec{D}}{\overrightarrow{\mathrm{D}}}$ any surgery, in thoracic aneurysms whenever 0 possible the operative field should be prepared for $\overline{0}$ at least two days before surgery. Unless the operation $\frac{\bar{m}}{7}$ is an emergency, we have adopted the policy of $\varnothing$ preparing the skin for two days by giving the patient a hot bath with soap and water and then applying an antibacterial, emullient detergent to the skin three times daily. Skin towels are routinely used at surgery and antibiotics are given in the 48 hours preceding surgery.

Organisms will grow and multiply in blood clot and dead tissue left behind after surgery. This danger can be minimized by adequate control of bleeding points, by washing the wound out several times with saline before closure, and by adequate drainage. When drainage tubes are used, however, it is important that they are not introduced near the site of the graft as the wound may act as an area through which the organisms can enter and infect the graft. It is best to introduce the drainage tube some distance away and then to lead it up to the graft area.

Routine use of post-operative antibiotics is important. In this series, penicillin and chloramphenicol were given on the first 10 days postoperatively.

Using these precautions, no infection was encountered.

SUMMARY

Four patients with aneurysms of the ascending aorta and four with aneurysms of the descending aorta, probably all syphilitic, were treated by surgery with complete cure in five and death in three.

Advanced disease was present in all, the patients presenting with superior mediastinal compression, arteriovenous fistula, erosion of the sternum, ribs, and vertebrae, massive haemoptyses, or obstruction to the pulmonary artery. Aortic incompetence was present in four, in one of whom it was gross. The three deaths occurred in patients submitted to emergency or semi-emergency surgery.

Retrograde angiography was most helpful in localizing the lesion and outlining the disturbed anatomy.

The factors essential for successful radical surgery are analysed and the methods employed are described.

Cure of acquired thoracic aortic aneurysm presents a varied and challenging problem to the surgeon, but the use of cardiac bypass, partial or total, with hypothermia has gone far to solve most of the difficulties. 
We wish to thank our surgical and medical colleagues of both the Cardiac Clinic and the Cardiothoracic Unit for their assistance with the investigation and treatment of patients, and the Medical Superintendent of Groote Schuur Hospital, Dr. J. G. Burger, for permission to publish. We also wish to thank Professor J. H. Louw, Professor of Surgery at the University of Cape Town, for his support and encouragement, and the technical staff of the J. S. Marais Surgical Research Laboratory for their assistance. Finally, we are indebted to the City Council of Cape Town, the Council for Scientific and Industrial Research, and the J. S. Marais and Fourcade Bequests of the University of Cape Town, for financial support.

\section{REFERENCES}

Abbott, O. A. (1949). J. thorac. Surg., 18, 435

Bahnson, H. T. (1953). Surg. Gynec. Obstet., 96, 383.

Bardenheuer (1885). Disch. med. Wschr., 11, 688.

Barnard, C. N., Terblanche, J., and Ozinsky, J. (1961). S. Afr. med. J., 35, 107

Churchill, E. D., Sweet, R. H., Soutter, L., and Scannell, J. G. (1950) J. thorac. Surg., $20,349$.

Clatworthy, H. W., and Varco, R. L. (1950). Proc. Soc. exp. Biol. (N.Y.), 74, 434.

Colt, G. H. (1927). Quart. J. Med., 20, 331.

Cooley, D. A., and DeBakey, M. E. (1956a). Bull. Soc. int. Chirg., 15, 206.

(1956b). J. Amer. med. Ass., 162, 1158.

- - - and Morris, G. C. (1957). Ann. Surg., 146, 473.

Corradi (1914). Quoted by R. Matas.

Cowley, R. A., Sloan, H. E., and Sullenberger, N. H. (1951). J. thorac. Surg., 21, 159.
DeBakey, M. E., Cooley, D. A., Crawford, E. S., and Morris, G. C. (1958). Ibid., 36, 393

De Takats, G., and Reynolds, J. T. (1947). Surgery, $21,443$.

Dunhill. T. P. (1922). Brit. J. Surg., 10, 4

Elkin, D. C. (1945). J. Amer. med. Ass., 129, 26.

- (1946). Ibid., 132, 421.

Gaertner, R. A., Spencer, F. C., and Bahnson, H. T. (1962). Progr. cardiovasc. Dis., 4, 373 .

Gerbode, F., Braimbridge, M., Osborn, J. J., Hood, M., and French, S. (1957). Surgery, 42, 975 .

Gordon-Taylor, Sir Gordon (1950). Brit. J. Surg., 37, 377.

Greenough, J. (1929). Arch. Surg., 19, 1484.

Harrison, P. W., and Chandy, J. (1943). Ann. Surg., 118, 478

Kocher, E. T. (1911). Text-book of Operative Surgery, 3rd English ed., vol. 2. Macmillan, New York.

Lam, C. R., and Aram, H. H. (1951). Ann. Surg., 134, 743.

Lane, J. D., and Peirce, E. C. II (1951). Surgery, 30, 709.

Lane, J. D., and Peirce, E. C. II (1951). Surgery, 30,

Mahorner, H., and Spencer, R. (1954). Ann. Surg., 139, 439.

Matas, R. (1888). Med. News, Philadelphia, 53, 462.

(1914). In Surgery, Its Principles and Prcictices, Vol. V, Chap. LXX. Saunders, Philadelphia.

Middleman, I. C., and Drey, N. W. (1951). Surgery, 29, 890

Milton, H. (1901). Lancet, 1, 242.

Moore, C. H., and Murchison, C. (1864). Med. Chir. Trans., 47, 129

Moore, C. H., and Murchison, C. (1864). Med. Chir.

Pearse, H. E. (1940). Ann. Surg., 112, 923.

Pontius, R. G., Bloodwell, R. D., Cooley, D. A., and DeBakey, M. E. (1955), Surg. Forum, 1954, 5, 224.

Brockman M. E. (1954). Surgery, 36, 33.

Poppe, J. K. (1948). Amer. Heart J., 36, 252.'

Rundle, F. (1937). Brit. J. Surg., 25, 172.

Sauerbruch, F., and Schumacker, E. D. (1911). Tecknik der Thoraxchirurgie. Springer, Berlin.

Schafer, P. W., and Hardin, C. A. (1952). Surgery, 31, 186.

Schrire, V., Beck, W., and Barnard, C. N. (1962). In preparation.

Schumacker, H. B., Jr. (1947). Surgery, 22, 729.

- (1948). Ann. Surg., 127, 464.

Terblanche, J., and Barnard, C. N. (1960). S. Afr. med. J., 341003

Wilson, H., and Carr, D. (1948). Surgery, $24,342$.

Yeager, G. H., and Cowley, R. A. (1948). Ann. Surg., 128, 509. 